\title{
Millennium Development Goals (MDGs) in Africa: The Role of an Ethno-botanist (Part 1)
}

\author{
Adekemi Omolayo Faboyede ${ }^{1}$, Olufemi Sosanya ${ }^{1}$ and Alaba Simpson ${ }^{2}$ \\ ${ }^{I}$ Department of Biological Sciences, Crawford University, Igbesa, Ogun State. Nigeria \\ ${ }^{2}$ Department of Sociology, Crawford University, Igbesa, Ogun State. Nigeria
}

\begin{abstract}
There are eight main MDGs and many stake holders in various countries have contributed to achieving some of these goals. Achieving the MDGs does not depend on economic growth and expensive solutions alone. Man himself has the solution very close to his bosom if he can make maximum use of what nature provides for him. Ethno-botany is an integral part of indigenous/local knowledge of a particular society. The ethno-botanicals accessed from forest areas not only provide a substantial amount of food security to the women but also play a significant role in securing the household economy. Women have developed local provisions of insurance of livelihoods for local communities, ethno-medicine for family health, growing of staple food crops, exploration of plant based innovations for food and biodiversity conservation. However, tens of thousands of plant species are at risk of being extinct, including plants used for food and nutrition, medicine, cultural and spiritual purposes, and the maintenance of livelihoods. These are needed to alleviate poverty, provide food security and ensure sustainable development in many nations. This paper focuses on the roles of an ethno-botanist in achieving some of the MDGs in Africa.
\end{abstract}

Key words: Ethno-botany, MDGs, anthropology, poverty alleviation, environmental sustainability

\section{Introduction}

Millennium Development Goals (MDGs) are no longer new. They are eight main goals with 21 targets and a series of measurable health and economic indicators for each target. Adopted by world leaders in the year 2000 and set to be achieved by 2015, they are both global and local, tailored by each country to suit specific developmental needs. They provide a framework for the entire international community to work together towards a common end i.e. making sure that human development reaches everyone and everywhere. If these goals are achieved, world poverty will be cut by half, tens of millions of lives will be saved and billions of people will have the opportunity to benefit from the global economy. The eight MDGs are (i) Eradicating extreme poverty and hunger (ii) Achieving universal primary education (iii) Promoting gender equality and empowering women (iv) Reducing child mortality rates (v) Improving maternal health (vi) Combating HIV/AIDS, malaria, and other diseases (vii) Ensuring environmental sustainability (viii) Developing a global partnership for development.

Many stake holders in various countries have contributed to achieving some of these goals. However, progress towards reaching the goals has been uneven. For example, some countries, such as Brazil, have achieved many of the goals, while others like Benin, are not even on track to realize any. The major countries that have been achieving their goals include China (whose poverty population has reduced from 452 million to 278 million) and India (due to clear internal and external factors of population and economic development). Recently, 38 Countries including Nigeria were commended by UN for meeting MDG hunger target [1]. Areas needing the most reduction, such as the sub-Saharan Africa regions are yet to make any drastic changes in improving their quality of life. Achieving the MDGs does not depend on economic growth and expensive solutions alone. Man himself has the solution very close to his bosom if he can make maximum use of what nature provides for him. For example, the varieties of life forms (e.g. micro- organisms, plants and animals) on earth i.e. biological diversity (biodiversity) is innumerable for man to use or manipulates.

\subsection{The Concept of Ethnobotany}

Since we arrived on the planet Earth, we've had relationships with plants. We eat, use as building materials and tools, weave fabrics, craft musical instruments, create art, make cosmetics and medicines from them. Plants inter-twine with our lives and contribute in a big way to our economy. If plants did not exist, human life would not be possible. All members of the human family depend on plants for their survival in many different ways. Today, we also depend on them for many of our opportunities to improve the quality of human life in the future. Plants are fundamental to the functioning of all human societies and to the operation of all ecosystems. Along with the photosynthetic bacteria and algae, plants are responsible for the formation of almost 
all of the energy that we consume. In terms of the energy from biomass that we are so actively seeking to develop now, they also provide the hope for energy supplies.

An inter-disciplinary field of study that recognises the knowledge that people posses about plants which is acquired through interaction with plants is known as Ethno-botany. Ethno-botany was defined as the study of direct inter-relations between humans and plants [2]. [3] broadly defined the subject as human evaluation and manipulation of plant materials, substances and phenomena in societies. Also, [4] related ethnobotany to the study of how people make use of plants. According to [5], it is the entire realm of useful relationship between plant and man. A more inclusive definition is the one given by [6] as the study of the uses, technological manipulation, classification, agricultural systems, magico-religious concept, conservation techniques, and general economic and sociological importance. These definitions point out that there is a relationship between people of a given community or society, the environment and the plant diversity in that particular community [7]. The goals of ethno-botanical research vary in different national contexts, and investigators are not always aware of the circumstances that have contributed toward the development of this discipline in other countries. Ethno-botany along with the related disciplines of ethno-biology and ethnoecology are of central importance for understanding and improving the sustainability of our relationships with the living world. The greatest resource that people have is their ability to innovate, and that ability is shared with all groups of humans who live or have lived on the Earth. Combining concepts derived from the disciplines of anthropology, agriculture, archaeology, biochemistry, genetics, horticulture, ecology, conservation biology, and botany, the field of ethno-botany holds extraordinary promise for helping us build a better future. Three areas of anthropologically oriented ethno-botanical research that is growing rapidly are: paleo-ethnobotany (recovery, identification and interpretation of archaeological plant remains), ethno-science (the study of indigenous taxonomic nomenclature with a goal toward elucidation of the cognitive principles of classification) and ecological anthropology (including ethnographic studies which explore the relationships among human populations and their exploitation of the natural environment).

\subsection{Ecological anthropology}

Ethno-botany is an integral part of indigenous/local knowledge of a particular society. Thus, different societies or communities have their own knowledge about plants and their uses. The rural people have developed unique indigenous knowledge related to the uses of plant resources due to constant association with the forests. In fact, indigenous knowledge systems are not only for the cultures from which they evolved, but also for scientists and planners striving to improve conditions in rural societies [8]. According to [9], the knowledge is the means by which most communities survived for centuries by adapting themselves to their environment, using their intrinsic knowledge of associated resource management.

Most ethno-botanists study how people of a particular culture or region make use of indigenous plants. This knowledge encompasses both wild and domesticated species. It is rooted in observation, relationship, needs, and traditional ways of knowing. Such knowledge evolves over time, and is therefore always changing and adding new discoveries, ingenuity and methods. The impacts of modern human societies on traditional cultures and natural habitats have caused huge losses of individual species, and profoundly disrupted communities of species (plant, animal and fungi).

In Africa, displaced or dispersed peoples (who may have passed along hundreds of generations of observations and customs via oral tradition) lose their languages, the names of things, and their place in the web of relationships. Sometimes new relationships develop as people migrate, and this generates new or modified ethno-botanical knowledge. Historically, ethno-botanists focused on either cultural use of plants or how a group of people perceived, classified and identified them [10]. Rural communities harvest plants to supplement their meagre income by producing items for industries and global market. Apart from these, many people (throughout the world) still rely on herbal medicine for their health care delivery.

Ethno-botany is very important because it traces the development of humanity. It also traces the development of modern Medicine and Herbalism, the Paper Industry, the Chemical Industry, Rubber Industry and Food Industry. Every year, new species are being discovered or are being reconsidered for modern applications in all the above Industries and Sciences. It has now become a concern of the modern world to preserve and gather all information on the utility of these plant species. Tens of thousands of plant species are at risk of being extinct, including plants used for food and nutrition, medicine, cultural and spiritual purposes, and the maintenance of livelihoods. These are needed to alleviate poverty, provide food security and ensure sustainable development in many nations. With the aforementioned, this paper therefore documents the invaluable roles of ethno-botanists in achieving the MDGs in Africa (especially in Nigeria).

\section{Ecological Anthropology Vs Mdgs}

Ecological anthropology includes ethnographic studies that explore the relationships among human populations and their exploitation of the natural environment. An ethno-botanist has a direct role to play in 
achieving MDGs. Following are some of the relationships among human populations and how they exploit the natural environment to achieve one or more MDGs:

\subsection{Role of Ethno-botanists in alleviating poverty and hunger}

Millions of people in many developing countries do not have enough food to meet their daily requirements and a further more people are deficient in one or more micronutrients [11]. However, ethnobotanicals accessed from forest areas, fallow lands and conserved in the kitchen garden not only provide a substantial amount of food security to the women but also play a significant role in securing the household economy. Plants collected by women and sold in the local market will generate cash income. Also, agriculture and livestock contribute major percent of income in Africa (since local people depend more on agriculture and livestock). In Nigeria for example, leafy vegetables and other bush foods are collected as daily supplements [12]. Various reports also noted that many wild edibles are nutritionally rich e.g. [13] and can supplement nutritional requirements, especially vitamins and micronutrients.

In Africa, plants with high nutritive values like: Colocasia esculenta, Basella alba, Telfairia occidentalis, Glycine soja, Gnetum africana, Arachis hypogea, and Solanum lycopersicum are cultivated mainly for commercial purposes, as they are sold in markets by women to earn income for the family. Others like Hibiscus sinensis and Moringa oleifera in addition to food and medicinal values, have become beautiful ornamental plants. Dracaena arborea, Anacardium occidentale, Spathodea campanulata, Allium sativum, Mucuna sloanei, Ocimum basilicum, Laportea aestuans, and Trema orientalis are used to treat constipation, indigestion, abdominal pain, and dysentery. Many authors classified Moringa oleifera (moringa) as miracle plant with multi-faceted activities. For example, in developing tropical countries, moringa trees have been used to combat malnutrition, especially among infants and nursing mothers. The leaves can be eaten fresh, cooked, or stored as dried powder for many months without refrigeration, and without loss of nutritional value. Moringa is especially promising as a food source in the tropics because the tree is in full leaf at the end of the dry season when other foods are typically scarce. Analyses of the leaf composition revealed them to have significant quantities of vitamins $\mathrm{A}, \mathrm{B}$ and $\mathrm{C}$, calcium, iron and protein [14]. For example; Moringa leaves contain: SEVEN times the vitamin C in oranges, FOUR times the Calcium in milk, FOUR times the vitamin A in carrots, TWO times the protein in milk and THREE times the Potassium in bananas.

Moringa seeds are substituting for alum in order to remove solids in water for drinking. After the oil is extracted from the pods, moringa seed-cake remaining contains the active components for removing turbidity (solid particles) from water. Because bacteria adhere to the solids, this seed-cake also effectively removes bacteria [15]. Not only is Moringa oleifera is as effective as aluminum sulphate (alum) in removing suspended solids from turbid water, it has a major advantage in that because it can be produced locally, using it rather than alum would save foreign exchange and generate farm and employment income. Use of this natural substance would also remove a source of aluminium contamination.

\subsection{Role of Ethno-botanists in promoting gender equality and empowering women}

In many rural societies of developing countries, women carry the burden of farm labour, arrange for household energy (mostly firewood from forest), collect food products from forest and arrange local plant based medicines to care for their children. During the period of hunger, women use the locally available indigenous plants for meeting the needs and help keeping their family alive. Women have developed local provisions of insurance of livelihoods for local communities, ethno-medicine for family health, growing of staple food crops, exploration of plant based innovations for food and biodiversity conservation [16].

A number of studies highlight that women suffer most when resources are degraded. In many communities and societies, women are at the forefront of conservation initiatives and a number of forest protection committees or natural resource management committees are all women, or have significant female leadership. Plant based biodiversity conservation efforts by traditional communities, primarily by women, include continuation of traditional conservation of local crops' species, collection and usage of forest based plants in daily dietary and medicines. These women have sustained and even revived and/or modified traditional plant based practices when faced with the pressure from various natural and social forces to their indigenous resources. It is well documented that traditional women and rural communities derive both their socio-cultural and spiritual identity from biodiversity. They have also developed their coexistence based on the sense of harmony with natural environment. Incidentally in Africa, women are treated as unequal with their male counterpart. Ethno- botany therefore is filling the gap of promoting and empowering them in the society. Their activities are brought to lime-light and thereby promoting their programmes.

\subsection{Role of Ethno-botanists in health care delivery}

The majority of people in developing countries depend on herbalists for their medical care. Even before the advent of conventional medicine in Africa, herbal or traditional medicine has been a major aspect of the 
socio-cultural heritage for hundreds of years. It was once believed to be primitive and wrongly challenged by foreign religions dating back to the colonial rule in Africa (and subsequently by the conventional or orthodox medical practitioners). Plant-derived medicines have been part of traditional health care in most parts of the world for thousands of years and there is increasing interest in them as sources in the treatment of diseases. [17] maintained that an effective health cannot be achieved in Africa by orthodox medicine alone unless it has been complemented with traditional medicine.

Tropical and subtropical Africa contain between 40-45,000 species of plants with a potential for development and out of which 5,000 species are used medicinally [18]. To date, $25 \%$ of modern medicines are derived from plants that have been used by traditional medical practitioners [19]. Still, there is a paradox, in spite of this huge potential and diversity, the African continent has only contributed 83 of the 1,100 classic drugs globally [18]. More than half of the world's population directly depends on natural resources for part or all of their livelihoods i.e. food, nutrition, medicines, water and many other needs (this include a high proportion of the poorest groups).

Species of Euphorbiaceae have been used by local populations of many countries in folk medicines as remedies against several diseases and complaints such as cancer, diabetes, diarrhoea, heart diseases, hemorrhages, gonorrhoea, urino-genital infections, jaundice hepatitis, malaria, ophthalmic diseases, rheumatism and scabies [20]. Following genera of Euphorbiaceae are reported as medicinal plants: Acalypha, Aleurites, Andrachne, Antidesma, Bridelia, Chrozophora, Hippomanae, Hura, Jatropha, Mallotus, Manihot, Phyllanthus, Putranjiva, Ricinus, Tragia and Trewia [21].

In Nigeria, a recent development in herbal medicine is the latest discovery of a PCR proven oral drug for HIV/AIDS treatment made from various plants extracts [22]. Another area of folklore which research supports is in cancer treatment. Moringa species have long been recognized by folk medicine practitioners as having value in the treatment of tumors. According to [23], the bark of Alstonia tree is one of the effective analgesic herbs available in nature. Therapeutically, the bark has been found to possess anti-rheumatic, antiinflammatory, analgesic/pain-killing, anti-malaria/antipyretic, anti-diabetic (mild hypoglycaemic), antihelminthic, antimicrobial and antibiotic properties. In some African countries, Alstonia boonei is considered a sacred tree and worshiped in the forest and hence human beings in those countries do not eat its parts.

The folkloric use of several plant species during childbirth in Nigeria has been validated. For example, [24] characterized seven plants to have contractile properties on uterine myometrial cells. Other diseases/sicknesses such as: Malaria, Fever, Anaemia, Stomach Ache, Skin Infection, Diabetes, Loss of Memory, and Prostate Cancer have been confirmed to be treated with the use of plants. The tender part of the stem of Vernonia amygdalina is used as chewing stick and the bitter water is swallowed daily as remedy for stomach ache. The leaves of Pawpaw are squeezed into one litre of water and a glassful is taken 3 times daily for 7 days to serve as a good treatment for malaria, fever and jaundice. Similarly, the green leaves are squeezed into 1 litre of water; one glassful is taken three times daily to treat diabetes and constipation. For intestinal ulcer, unripe pawpaw fruit is cut into pieces and the peel and seeds are removed and soaked in five litres of water for 4 days. It is sieved and $1 / 2$ glass is taken 3 times daily for two weeks. The white milky sap of unripe pawpaw contains a high percentage of papain which is used for chronic wounds or ulcers. The dry fallen leaves are washed and ground into powder. Two tablespoonfuls of the ground powder are added into 1/2 glass of palm kernel oil, stirred properly, and rubbed over the body to arrest high fever and convulsion.

In order to cure anaemia, intestinal ulcer, and heart problem, the dried peels of Musa paradisiaca are ground into powder; one tablespoon of the powder is mixed with four tablespoons of honey and licked three times daily for two weeks for intestinal ulcer. Some quantity of the root and fresh leaves are boiled separately; $1 / 2$ and a full glass is drank daily for 1 week to intestinal ulcer and anaemia, respectively. Eating of unripe fruit either roasted, boiled, pounded, or processed into flour is a good treatment for diabetes.

For Cough, Malaria Fever, and repellents, decoction from leaves of Cymbopogon citrata with onion and honey is used. The leaf is boiled along with other herbs to treat malaria fever by bathing with it every night for 2 days. The leaf is burnt in homes to serve as repellant for mosquitoes. Also for fever and lactation, The bark, root, and leaf of Morinda lucida are used in infusion or decoction for the treatment of yellow fever and other forms of fever to be taken $1 / 2$ glass, 2 times daily, and also bathing, for 3 days. The leaf decoction is applied to the breast of women at weaning of their infants to improve lactation. Twigs are used as chewing stick.

In treating malaria, diabetes, dysentery, Mouth Thrush, Toothache, and Sore Gums, the twig of Anacardium occidentale is used as chewing stick for mouth thrush, tooth ache, and sore gum. Decoction of the bark is a remedy for malaria fever, by drinking $1 / 2$ glass 3 times daily. The bark and leaves are boiled, and a glass is taken twice daily for dysentery. In order to treat Fibroids, Cataract, Gonorrhea, Aphrodisiac, Cough, Inflammatory Symptoms, Toothache, and Sore Throat, Seed of Spondias mombin is boiled together with immature palm-nuts and $1 / 2$ glass is taken thrice daily for 2 months for fibroid. Fresh leaves are ground and the juice is squeezed and mixed with one teaspoonful of lime juice and applied as eye drop twice daily for cataract. 
Fresh leaves are boiled and one glassful is drank thrice daily for gonorrhea. Decoction of leaves is used as an aphrodisiac. Decoction of the bark is taken for severe cough, toothache, and sore throat.

Another useful plant is Ageratum conyzoides in the treatment of Abdominal Pains, Ulcers, Skin Disease, Dressing of Wound, and Prophylactic. Decoction of the whole plant of Ageratum conyzoides is a remedy for abdominal pains. Leaf juice is used for dressing wounds, ulcers, and other skin diseases. Leaves are used as tonics to aid fertility, because it prevents early miscarriage. It is also used as prophylactic and cure for trachoma in cattle. In treating threatened abortion, convulsion, epilepsy, skin infections, conjunctivitis, migraine, and earache. A medium size pot is filled with the fresh bark of Newbouldia laevis and boil in water for a long time. The preparation is then used to wash face and head every morning and night; oral taking of $1 / 2$ glass of preparation twice daily for 6 days cures migraine and also stops vaginal bleeding in threatened abortion. Leaves and roots are boiled together and administered for fever, convulsion, and epilepsy. Stem bark is used for treating skin infections. Decoction of leaves is used as an eye wash in conjunctivitis. Boiled leaves extract is used to treat general malaria. The fruit of Ananas comosus is cut, cooked, and drank for typhoid fever. The unripe fruit can be used as a purgative, diuretic, antihelmintic, expectorant, and abortifacient and is also taken to regulate and enhance menstrual flow. Fruit peel is used topically for healthy skin. The ripped fruit is taken regularly to recover from typhoid fever.

Fruits of Citrullus colocynthis are recommended for the treatment of stomach troubles and sexually transmitted diseases. Fruit and leaf decoction is used as a purgative in man and animal. Seed shell powdered and mixed with palm oil is rubbed on skin to treat fungal infections. The latex of Jatropha curcas is used to treat skin disease such as ring worm, scabies, and eczema. Twigs are used as chewing stick to prevent tooth decay, oral thrush, bleeding, wounds, and tooth ache. Roots are used to treat sexually transmitted diseases. Leaves are added to hasten fermentation of cassava. Decoction of leaves is used to sterilize umbilical cord of new born babies. Seed of Tetracarpidium conophorum is used in the treatment of fibroid. Boiled seeds are eaten to improve sperm count in men. Leaf juice is used to improve fertility in women and to regulate menstrual flow. Leaves of Telfairia occidentalis are of high nutritive value as vegetable for soup and other local dishes. Leaves are washed and the juice squeeze is mixed with milk and taken as a blood tonic. The boiled seeds are eaten as delicacy and source of oil.

\subsection{Roles of Ethno-botanists in Ensuring environmental sustainability}

Sustainability is defined as the use of resources at a rate slower than that at which they are being created. Building sustainability depends not only on our use of the environment, but also on cultural, political, and economic considerations. Our collective management of the world's resources is unsustainable at present. Rapidly rising population levels, the runaway growth of individual consumption, and the continued use of inappropriate technologies are progressively limiting the options for the future, and the kind of world that our descendants will inhabit. The application of ethno-botany is a possible way of breaking free of our passive approach to the world and dealing with this seemingly overwhelming set of challenges in a positive way. Such vital environmental resources as the air we breathe, the quality of the water we drink, the topsoil upon which our agriculture depends, the relatively stable global climate we have enjoyed until recently, and the global stock of biodiversity are all being degraded rapidly. Concurrently, the diversity of human cultures is being eroded rapidly everywhere. For example, every week one of the remaining 7,000 languages is being lost. To reverse these trends, we need to respect the wisdom of the diverse approaches to nature that exist in every society. This knowledge is central to the preservation of the integrity of the cultures that possess it, and important for us all to understand, record, and, when appropriate and helpful, apply in other situations.

The strong links between biological and cultural diversity uniquely position ethno-botany to help us craft effective local solutions to many of the global issues that confront us as a species. Some of the most challenging of these issues are food security, deforestation, pollution, the maintenance of human health, the quality of human life, and resource depletion of all kinds. Varieties of life forms on earth i.e. biological diversity or biodiversity is innumerable for man to use or manipulates. Instead, man is losing (depleting) it at an alarming rate. Loss(depletion) of biodiversity results in serious reductions in the goods (such as food, medicine and raw materials) and services (such as clean water and nutrient cycling) provided by the earth's ecosystems, which make human survival and economic prosperity possible [25]. Biodiversity plays an important role in ensuring that the targets of the MDGs for sustainable development are successfully achieved. The direct economic benefits of biodiversity run into trillions of dollars per year [26].

However, in many areas, traditional systems of indigenous resources use and management have broken down in response to the processes of globalization, inappropriate policies, and a host of threats from wider economic and political forces. The links between biodiversity and the path to achieving the MDGs have not been made explicit [27]. For a very large number of developing countries, the predominant national agenda is to improve the livelihood and welfare of their citizens; environmental concerns are viewed as secondary. The loss of provisioning resources, such as food, has increased poverty and hunger around the world. The degradation of 
regulating services that ecosystems provide thus affected the health of millions of people. Supporting services have also been reduced to farmlands and they have become overexploited.

Currently, man is consuming more resources than the earth can sustainably provide. For example, in major cities around the world, we are consuming as much as 10 times the earth's carrying capacity [28]. The result is that humans are passing critical thresholds, leading to the unravelling of basic ecosystem services and functioning. A recent study found that three of nine planetary life support systems have already been exceeded, and several others are fast reaching their limits [29]. Therefore, loss of biodiversity is a major barrier in fulfilling the MDGs. An ethno-botanist has a role to play in bridging this gap. The indigenous knowledge of lives ( both flora and fauna) is very important and how to preserved and conserve them is very crucial. In achieving this goal therefore, an ethno-botanist will not fold his hands but cry out and relates with the local people. He therefore bridges the gap by involving them in the conservation efforts.

\section{Conclusion}

Ethno-botany can strengthen our links to the natural world. It makes it possible for us to learn from the past and from the diverse approaches to plants represented by the different human cultures that exist today. It is a vital key to preserving the diversity of plants as well as to understanding and interpreting the knowledge by which we are, and will be enable to deal with them effectively and sustainably throughout the world. Therefore, it is of paramount importance for ethno-botanists to communicate this indigenous knowledge to policy makers and various industries and develop a partnership on development. A new global programme is needed to mainstream ethno-botany into development and to place local communities' needs. Also, in academic ethnobotanical research, efforts should be made to preserve local ownership of knowledge in a culturally sensitive manner and to include local communities at all levels of conservation. Many ethno-botanists, in attempt to justify their scientific credentials to more established fields, often focus on research and high-impact journals at the expense of local community engagement - tendencies that are unethical and inhibit successful conservation. Scientists must accept local populations' rights to own their knowledge, and take steps to publish results in local languages and providing opportunities to collaborate in research and policy discussion.

[1] THISDAY LIVE (2013) http://www.thisdaylive.com/articles/nigeria-37-others-bag-un-award-for-meeting-mdgs-hungertarget/150734/ (Accessed August 3, 2013).

[2] R. J. Ford, Ethnobotany: Historical diversity and synthesis in R.J. Ford (Ed.), The Nature and status of ethnobotany, Anthropological papers, (University of Michigan, Ann Arbor : Museum of Anthropology, 1994).

[3] R.E. Schultes and R. F. Raffauf, The Healing Forest. (Dioscorides Press, Portland, 2003).

[4] S. K. Jain, Dynamism in ethnobotany, Ethnobotany, 17(122), 2005, 20-23.

[5] P. Pushpangadan and B. Kumar, Ethnobotany, CBD, WTO and the Biodiversity Act of India. Ethnobotany, 17, $2005,2-12$.

[6] R. E. Schultes, The importance of ethnobotany in environmental conservation. American Journal of Economics and Sociology.56(2), 1994, 202-206.

[7] M. E. Osawaru and F. M. Dania-Ogbe, Ethnobotanical studies of West African okra (Abelmoschus caillei (A. Chev) Stevels) from some tribes of South western Nigeria. Science World Journal 5 (1), 2010,

[8] P. Shengji, Ethnobotany for biodiversity conservation in B. R. Bhatta, S. R. Chalise, A. K. Myint, and P. N. Sharma (Eds.), Recent concepts, knowledge, practices and new skill in participatory integrated watershed management trainers (Resource Book, FAO, ICIMOD, PWMT A, 1999).

[9] D. M. Warren and Cashman, Indigenous knowledge for sustainable agriculture and rural development, Gatekeeper series SA (10), (Interact Institute for Environment and Development (HED), London, 1988).

[10] J.S. Thomas, Carlson and M. A. Luisa, Review of Ethnobotany and Conservation of Bio-cultural Diversity, Advances in Economic Botany (15), 2005

[11] Food and Agriculture Organization of the United Nations (FAO), The State of food insecurity in the world. Monitoring the progress towards the world food summit and millennium development goals. Annual Report. Rome. 2004.

[12] R, Loghurst, Household food strategies in response to seasonality and famine.

[13] P. M. Maundu, G. W. Ngugi, and C. H. S. Kabuye, Traditional food plants of Kenya. (National Museums of Kenya, Nairobi, 1999).

[14] P. Donovan, Moringa oleifera : The Miracle Tree (online) Available at http://www.naturalnews.com/022272_Moringa_medicinal_herbs.html Accessed on August 12013

[15] G. K. Folkard and J. P. Sutherland, Moringa oleifera - A tree and a litany of potential. Agroforestry Today, 8 (3), $1996,5-8$.

[16] R. K. Singh, A. Singh, and A. K. Sureja, Sustainable use of Ethno-botanical resources. Indian Journal of Traditional Knowledge 6(3), 2007, 521-530

[17] A. A. Elujoba, O. M. Odeleye and C. M. Ogunyemi, Traditional Medical Development for medical and dental primary Health care Delivery System in Africa. African Journal of Trad., CAM. 2(1), 2005, 46-61.

[18] B. E. Van Wyk, A broad review of commercially important Southern African medicinal plants, Journal of Ethno-pharmacology, 119 (3), 2008, 342-355.

[19] G. M. Cragg and D.J. Newman, Plants as a Source of Anti-Cancer Agents. Ethnopharmacology(1), 2005

[20] M. Siwakoti and S. K. Varma, Medicinal plants of the Terai of Eastern Nepal. J. Econ. Taxon. Bot. Additional series (12), 1996, $423-438$.

[21] R. N. Chopra, S. L. Nayar, and I. C. Chopra, Glossary of Indian Medicinal plants (CSIR, New Delhi), 1992.

[22] Anonymous, Herbal treatments; AID/HIV Nigeria, http://www.pcr-proven-hiv-cure.com/herbal-aids-medicine-nigeria.html (Accessed August 1,2013).

[23] J. P. K. Adotey, G.E. Adukpo, Y.O. Boahen and F. A. Armah, A Review of the Ethnobotany and Pharmacological Importance of Alstonia boonei De Wild (Apocynaceae), ISRN Pharmacology 2012, 2012 
[24] A. F. Attah, M. O'Brien, J. Koehbach, M. A. Sonibare, J.O. Moody, T.J. Smith and C. W. Gruber, Uterine contractility of plants used to facilitate childbirth in Nigerian ethno-medicine. J. Ethnopharmacol. 143(1), 2012, 377-382.

[25] Anonymous, Poverty and Climate Change: Reducing the Vulnerability of the Poor, Interagency discussion paper (World Bank, Washington, 2002).

[26] R. Constanza, R. d'Arge, R. de Groot, S. Fabes, M. Grano, B. Hannon, K. Limburg, S. Naeem, R. V. O’Neil, J. Pareulo, R. Raskin, P. Sulton and M. Van der Belt, The value of the world's ecosystem services and natural capital. Nature 387, 1997, 254-260.

[27] WRI, 2002: Why Care about Ecosystems? http://www.wri.org/wr2000/why care.html ( Accessed July 30, 2013)

[28] W. Rees and M. Wackernagel, Urban ecological footprints: Why cities cannot be sustainable - And why they are a key to sustainability. Environ. Impact Assess. Rev., 16, 1996, 223-248.

[29] F. Pearce, The Coming Population Crash: And Our Planet's Surprising Future. (Beacon Press, 2010) 289pp. 